\title{
In-Situ TEM Self-Ion Irradiation and Thermal Aging of Optimized Zirlo
}

\author{
B. Muntifering ${ }^{1,2}$, P.-A. Juan ${ }^{2}$, R. Dingreville ${ }^{2}$, J. Qu ${ }^{1,3}$, and K. Hattar $^{2}$ \\ ${ }^{1 .}$ Department of Civil and Environmental Engineering, Northwestern University, Evanston, IL, USA \\ 2. Sandia National Laboratories, Albuquerque, NM, USA \\ 3. School of Engineering, Tufts University, Medford, MA, USA
}

The aggressive environments of nuclear reactors present a wide range of material difficulties due, in particular, to neutron radiation and elevated temperatures. Zirconium alloys are commonly used as nuclear fuel cladding due to their nuclear cross-section and high resistance to corrosion; however, neutron irradiation can result in hardening and swelling of zirconium alloys in certain temperature regimes [1]. In this study, we examined the effects of irradiation of commercially available Optimized Zirlo with zirconium ions in order to characterize microstructural evolution as a result of self-ion induced displacement damage. The evolution of the defects was characterized during post-irradiation annealing. Microstructural evolution of grain and precipitate structure and boundaries as a result of irradiation was studied using ASTAR orientation mapping.

Jet polished Optimized Zirlo samples were in situ self-ion irradiated utilizing a JEOL 2100 TEM and a 6 MV Tandem ion accelerator that are part of the In situ Ion Irradiation TEM (I TEM) facility at Sandia National Laboratories [2]. The implantation occurred in a hummingbird heating stage tilted $40^{\circ}$ towards the $3 \mathrm{MeV}$ zirconium ion beam operated at an average flux of approximately $8 \times 10^{10} \mathrm{Zr}^{3+} / \mathrm{cm}^{2} \mathrm{~s}$ for 4.5 hours, resulting in approximately 10 DPA. The sample was then heated in a hummingbird heating stage at a rate of $4^{\circ} \mathrm{C} / \mathrm{min}$ to $750^{\circ} \mathrm{C}$.

Figure 1 shows a series of bright field TEM images of optimized zirlo which was self-ion irradiated at room temperature and then annealed to $600{ }^{\circ} \mathrm{C}$. A high density of small dislocation loops were present at room temperature which were observed to grow to over $20 \mathrm{~nm}$ in size by $600{ }^{\circ} \mathrm{C}$. No cavities were visible at any temperature. At $700{ }^{\circ} \mathrm{C}$ a phase transformation occurred, but the dislocation loops did not anneal out. ASTAR orientation mapping was performed and Figure 2a is an index map from 250-1000 of irradiated Optimized Zirlo. A high density of precipitates were present at both the grain boundaries and matrix, several of which are highlighted with black arrowheads. Figure $2 b$ shows the orientation map, demonstrating the strong [0001] texture present in these samples. The area around the inclined grain boundaries indexed incorrectly as a separate orientation, and work is underway to remove these types of artefacts. Efforts are underway to identify the structure of the precipitates and characterize their orientation. These results will be directly compared to a micromechanical formulation accounting for the various mechanisms experimentally observed.

References:

[1] C. Lemaignan and Arthur T. Motta. "Zirconium alloys in nuclear applications." Materials Science and Technology (1994).

[2] K. Hattar, et al. Nuclear Instruments and Methods in Physics Research B 338 (2014).

[3] This work is funded by NEET through DE-NE0000678. Sandia National Laboratories is a multiprogram laboratory managed and operated by Sandia Corporation, a wholly owned subsidiary of Lockheed Martin Corporation, for the U.S. Department of Energy's National Nuclear Security Administration under contract DE-AC04-94AL85000. 

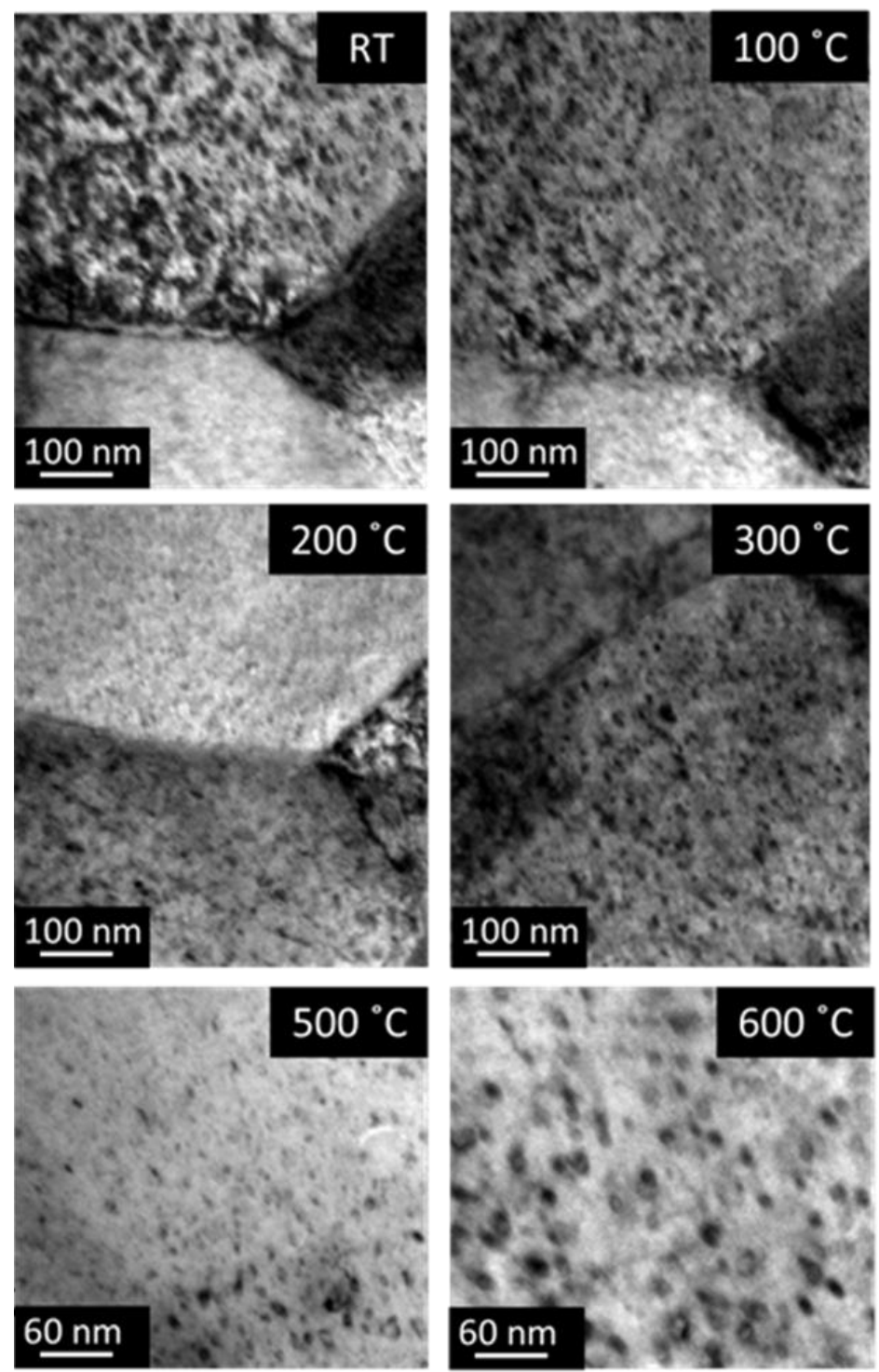

Figure 1. Optimized Zirlo irradiated to $10 \mathrm{dpa}$ with $3 \mathrm{MeV} \mathrm{Zr}$ ions at room temperature. The sample was then annealed to $600^{\circ} \mathrm{C}$. Dislocation loops grew with temperature to over $20 \mathrm{~nm}$.

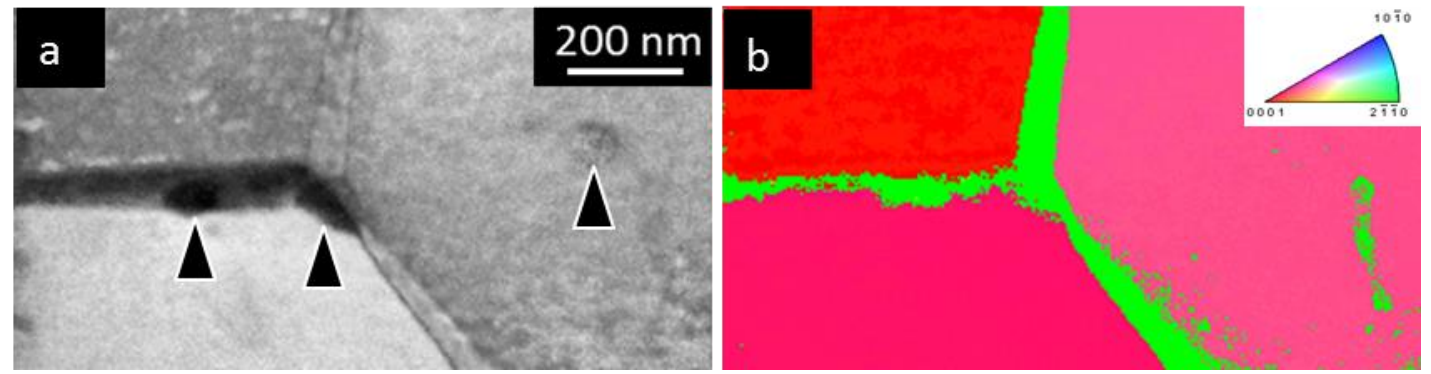

Figure 2. a) Index map from 250 -1000 and b) orientation map of irradiated optimized zirlo. Several percipitates are highlighted with arrowheads. 